\title{
Venous thrombosis - the importance of cardiovascular disease as a risk factor
}

\author{
Ljiljana Banfićc, Zoran Miovski, Davorka Čapalija, Majda Vrkić Kirhmajer \\ University of Zagreb School of Medicine, University Hospital Centre Zagreb, Zagreb, Croatia
}

Objectives: The aim of the study was to reveal demographic data, laboratory and vein duplex findings in patients hospitalized for venous thrombosis and thromboembolism. Specific interest was focused on usual laboratory findings such as D-dimer, coagulation cascade parameters and thrombophilia investigation and its relationship with the severity of deep vein thrombosis (DVT). Risk factors such as cardiovascular diseases, malignancy, trauma, metabolic parameters and other well known data were analyzed. The increasing incidence of venous thrombosis in ageing population has changed the priority list and the importance of usual risk factors.

Patients and Methods: The study included all patients with clinical suspicion for DVT and or/pulmonary embolism (PE), treated in the University Hospital Centre Zagreb through the period of 52 months. Three hundred twenty-four patients with venous thrombosis and/or pulmonary embolism were analyzed. Antropometric, biochemical and lipid parameters, hypercoagulability factors, malignancy, trauma or surgery, cardiovascular disease, DVT family history, previous DVT or PE were evaluated. Patients were grouped according to the vein thrombosis location. Diagnosis of DVT was done with duplex scan. PE was diagnosed on MSCT pulmonary angiography or lung ventilation-perfusion scintigraphy.

Results: DVT was diagnosed in 264 (81.5\%) and PE in 80 patients $(24.7 \%)$. Only 46 patients suffering from PE had evidence of venous thrombosis on the limb duplex scan. The femoral and popliteal veins were the most common sites of thrombi. The frequency of patients older than 55 years was $68.2 \%$. Similar incidence was found in both sexes. The evidence of cardiovascular disease was the most frequent risk factor (47.8\%). Malignancy was found in 62 patients $(19.2 \%)$. The incidence of previous surgery or any trauma was $17 \%$. Thrombophilia as the only risk for venous thrombosis was revealed in 63 patients. Proximal DVT was most extensive in the older age group $(P<0.0001)$. D-dimer values had significant positive correlation with thrombosis severity $(\mathrm{P}<0.0001)$.

Conclusion: Cardiovascular disease had the highest incidence in population suffering from venous thromboembolism. This finding emphasized the importance of careful preventive strategies in patients with cardiovascular disease. In clinical settings, higher levels of D-dimer could implicate proximal deep venous thrombosis.

KEYWORDS: thrombosis, risk factors, cardiovascular disease.

CITATION: Cardiol Croat. 2013;8(9):312.

\section{Received: $1^{\text {st }}$ Aug 2013}

*Address for correspondence: Klinički bolnički centar Zagreb, Kišpatićeva 12, HR10000 Zagreb, Croatia.

Phone: +385-1-2367505

E-mail: ljiljana.banfic@zg.t-com.hr

\section{Literature}

1. Guyatt GH, AkI EA, Crowther M, et al; American College of Chest Physicians Antithrombotic Therapy and Prevention of Thrombosis Panel. Executive summary: Antithrombotic Therapy and Prevention of Thrombosis, 9th ed: American College of Chest Physicians Evidence-Based Clinical Practice Guidelines. Chest. 2012;141(2 Suppl):7S-47S.

2. Rooke TW, Hirsch AT, Misra S, et al; Society for Cardiovascular Angiography and Interventions; Society of Interventional Radiology; Society for Vascular Medicine; Society for Vascular Surgery. 2011 ACCF/AHA Focused Update of the Guideline for the Management of Patients With Peripheral Artery Disease (updating the 2005 guideline): a report of the American College of Cardiology Foundation/American Heart Association Task Force on Practice Guidelines. J Am Coll Cardiol. 2011;58(19):2020-45. 